\title{
Course-Based Learning Outcomes as the Foundation for Assessment of Graduate Attributes
}

\author{
Darlene Spracklin-Reid, P.Eng \\ Senior Instructional Designer \\ Distance Education, Learning and Teaching Support, Memorial University \\ darlenesr@mun.ca \\ Andrew Fisher, P.Eng \\ Associate Dean (Undergraduate Studies) \\ Faculty of Engineering \& Applied Science, Memorial University \\ adfisher@mun.ca
}

\begin{abstract}
In 2010, the Canadian Engineering Accreditation Board (CEAB) began reviewing programs for progress toward assessment of graduate attributes. This represented a significant change from traditional inputs-based to outcomes-based accreditation. As engineering schools across Canada are considering how to meet the CEAB requirements, this paper provides details on the approach taken by the Faculty of Engineering and Applied Science at Memorial University and, in particular, the development of course-based learning outcomes.
\end{abstract}

\section{Introduction}

The development of comprehensive learning outcomes for all core courses in the engineering program is the foundation for Memorial University's approach to the Canadian Engineering Accreditation Board's (CEAB) outputs-based accreditation [1]. The assessment of program outcomes, or graduate attributes, is substantially achieved through the assessment of the course-based learning outcomes that contribute to attribute development.

Graduate attributes are a composite of knowledge, skills and attitudes that are developed and demonstrated at various levels throughout the program [2]. Measureable learning outcomes allow for the assessment of graduate attributes as they form thus becoming an essential component for quality assurance and continual improvement of the program. Without comprehensive learning outcomes, gaps in attribute acquisition as students progress through the program cannot be identified. Without comprehensive learning outcomes, curriculum maps will not provide the detail required to identify gaps in the program.

Documenting course-based learning outcomes identifies opportunities for improvement that might not be apparent using a top-down approach of assigning graduate attributes or broad indicators to courses. Using course-based learning outcomes, we are identifying opportunities to implement small changes that have big impacts. This approach allows the faculty to be "intentional" about the development of graduate attributes.

Faculty, staff and students work collaboratively to develop learning outcomes, assessment techniques and curriculum maps. Based on these, graduate attributes are identified, assessed and continuous improvement is facilitated. The goal is not only to exceed the CEAB requirements, but also to use the process as an opportunity to reflect on, encourage and implement best-practices in teaching and learning.

\section{Graduate attributes as program outcomes}

The change from inputs-based to outcomes-based accreditation doesn't mean that Canadian engineering schools have been getting it all wrong. However, it does mean that we are changing the lens through which we examine our programs. Memorial's approach to meeting the CEAB's requirements requires taking a detailed look at what we have been doing, evaluating that against the CEAB's graduate attributes and moving forward by addressing specific gaps highlighted by this process

Teaching and learning communities are comprised of students, faculty and staff. In Memorial's outcomes-oriented teaching and learning community, these parties work together to identify the knowledge and skills students must possess in order to demonstrate the required graduate attributes. [3]

Graduate attributes are program outcomes, and program outcomes are built upon course outcomes. Authentic assessment of graduate attributes can be achieved if they are linked to course based outcomes that are measureable indicators of learning and skill acquisition. 


\subsection{Developing learning outcomes}

For each course in Memorial University's Faculty of Engineering and Applied Science, specific, achievable and measureable learning outcomes are being developed. These learning outcomes are statements that describe what a student will know, or what they will be able to do, upon completion of the course. The development of learning outcomes has been a collaborative process based on accepted learning theories, such as Bloom's Revised Taxonomy [4][5], within each engineering discipline, with support, feedback and input from students and staff.

These learning outcomes form a comprehensive picture of the types of learning that is occurring within the program, where that learning occurs, and the level at which it is occurring.

The learning outcomes are developed by individual professors and shared with the discipline group and instructional design staff for input. Data from student focus groups is also used to inform this curriculum design and review process. Learning outcomes belong to the discipline, and can be reviewed, updated and edited within the group.

With emphasis placed on the learning outcomes, and not the learning process, academic freedom is maintained. With ownership and control of the development and maintenance of the outcomes remaining within each discipline, the flexibility to respond to required changes is facilitated while maintaining accountability to the $\mathrm{CEAB}$ requirements.

\subsection{Assessment of learning outcomes}

Learning outcomes must be measurable. In the development of course-based learning outcomes, associated assessments are also developed. Assessments are learning activities or exercises designed to obtain evidence of student achievement of learning outcomes. Common engineering assessments include laboratory work, projects, assignments, final examinations, or presentations [6].

Support for the design of assessment tools such as ePortfolios and rubrics is provided by Instructional Designers and Teaching Consultants from Memorial University's Distance Education Learning and Teaching Support (DELTS) division, and is informed by student feedback through surveys and focus groups. Teaching and assessment toolkits for each graduate attribute are in development to support faculty in delivering and measuring related learning outcomes. The toolkits are a collaborative effort by faculty, staff and students and will consist of multi-media resources accessible through existing online course shells.

For example, the toolkit for CEAB's Individual and Team Work attribute will have multi-media content supporting the development of leadership and effective team work skills, along with assessment tools including rubrics, self-assessments, suggested assignments, and learning activities. Content is being developed collaboratively with faculty and with students who have made significant contributions by providing feedback and suggestions for ways they feel they can best demonstrate their knowledge and skills. Content can be used as-is, or modified and reposted to share.

By linking assessments to course-based learning outcomes, we are able to monitor the development of graduate attributes as it occurs, allowing for formative assessments to guide that development. Rather than only examining the final product, assessing graduate attributes as they develop creates opportunities for improvement as students progress through the program.

\subsection{Linking graduate attributes}

As specific course-based learning outcomes and assessments are created, they are linked to graduate attributes in our database approach to curriculum mapping. As the learning outcomes are measured, graduate attributes are being measured.

The database, and the curriculum map it informs, is searchable by graduate attribute. A search for a specific graduate attribute tells the user the courses in which that attribute is being developed, the specific learning outcomes or indicators associated with that graduate attribute, and how those outcomes, and therefore the graduate attribute, are being measured.

This bottom-up approach ensures that a comprehensive curriculum map is created, we can track graduate attributes as they develop, and measure that development as it occurs. It allows for quality assurance of the program, and facilitates continuous improvement.

\subsubsection{Linking graduate attributes, outcomes and assessments in ENGI 7102}

ENGI 7102: The Engineering Profession, includes the following learning outcomes:

- document your own attempts to meet the profession's criteria for success, and critically evaluate the effectiveness of your efforts, 
- evaluate your own career path and expectations in relation to the standards of professional conduct,

- communicate technical information in a clear, effective, and professional manner using oral, written, and graphic delivery methods. [7]

As their first assignment, students create an autobiographical map, a visual representation of the path that led them study engineering. They also construct an action plan to achieve future professional goals. There is an associated rubric that is provided for the students to clarify how their maps will be assessed [7].

This assessment activity measures, in part, the outcomes above. In turn these outcomes are linked to graduate attributes such as communication skills, professionalism, and lifelong learning. A search in the database supported curriculum map for lifelong learning would reveal that this graduate attribute is partially developed in ENGI 7102, with specific indicators in the form of course-based learning outcomes and details about the assessment tool and its associated rubric. It should be noted that students are introduced to these concepts at the beginning of second year (ENGI 3101) and are given guidance on the technical details of e-portfolios as well as techniques like reflective learning.

\subsection{Impact on teaching and learning}

Developing learning outcomes and assessments, creating links to graduate attributes and mapping the curriculum has provided Memorial's Faculty of Engineering and Applied Science with the opportunity to reflect on best practices in teaching and learning. As faculty come together to describe what students will know, or be able to do, upon completion of a course, how best to instruct and measure becomes part of the process.

Faculty, staff and students have been working together to develop new and creative ways of instructing and assessing. The course-based learning outcomes, and how they will be assessed, are shared with the students, giving them the ability to see how their learning is developing and to become active participants in their own learning. It develops their reflective skills, and their ability to identify areas for further development as required by CEAB's lifelong learning graduate attribute.

One of the advantages of this new approach is that it allows for recognition of learning that occurs outside of the classroom (e.g. work terms, student society leadership, EWB, etc). By bringing these aspects into focus, other opportunities for student engagement are beginning to emerge.

\subsection{Conclusion}

There is still a significant way to go before this new approach is fully realized and then, presumably, a lifetime of continuous improvement. Despite the length of the journey, it is clear that the imposition of a new approach to accreditation by CEAB is providing motivation and opportunity for Canadian engineering faculties to make a step-change in teaching and learning practices. The approach at Memorial University has been to see this as a chance to significantly enhance our understanding of how learning is occurring, to be intentional and transparent about how we are developing graduate attributes and to institute a process that will provide a basis for continuous improvement. The collaboration of students, instructional development staff and faculty has provided a wealth of new ideas and new sense of our shared interest in teaching and learning best practices.

\section{References}

[ 1 ] Engineers Canada, Canadian Engineering Accreditation Board, "2010 Accreditation Criteria and Procedures”, www.engineerscanada.ca, 2010.

[2] Simon C. Barrie, "A research-based approach to generic graduate attributes policy.” Higher Education Research \& Development, 31:1, 79-92, 2012.

[3] A comprehensive framework for teaching and learning at Memorial University, May 10, 2011. Available as of May 14, 2012 from http://www.delts.mun.ca/faculty/teachinglearning/TLF _May_2011_FINAL_Framework.pdf

[4] David R. Krathwohl, “A Revision of Bloom's Taxonomy: An Overview,” Theory Into Practice, 41:4, 212-218, 2002.

[5] L. W. Anderson and D.R. Krathwohl, (eds.), A taxonomy for learning, teaching, and assessing: A revision of Bloom's taxonomy of educational objectives. NewYork: AddisonWesley Longman, 2001.

[6] O.A.B. Hassan, Learning theories and assessment methodologies - an engineering educational perspective," European Journal of Engineering Education, 36:4, 327-339, 2011.

[7] J. Rosales, private communication, May, 2012. 